\title{
Educational Theories of Cognitive Development
}

\author{
Mona Aeysha Khalid \\ Kinnaird College University, Pakistan \\ Email: mei3na4@gmail.com
}

Doi:10.5901/jesr.2015.v5n1p313

\begin{abstract}
Cognitive theories explain how behavior changes as a result of people's perception, transformation, processing, storage and retrieval of information in contrast to behaviorist who focus on only observable facts. Cognitive psychologist, instead, claim that they could access to internal psychological processes through applying scientific techniques and systematic verifiable procedures to study human behavior at its best. In the present paper, we will examine how both schools of thought provide us with a rich and descriptive data to enhance learning among pupils and to fulfill their healthy cognitive and emotional developmental needs that is a milestone in their journey towards becoming a successful and confident individual in future.
\end{abstract}

Keywords: educational theories, cognitive development, learning strategies, educational implication, behavioral theories

\section{Introduction}

Learning involves understanding, interpreting, reflecting, and reinforcing the present knowledge, experience, skills, values, concepts, and preferences. It is calculated through synthesizing and following a pattern of growth and development by humans, animals, or other non-living objects. It should be taken as a process rather than a combination of facts and theories. Thus, it ensures certain changes in behaviors of almost permanent nature (Daniel et al, 2009). This paper will explore key schools of thoughts of learning to achieve the following objectives:

a. What is the real nature of learning with respect to historical background?

b. How can we relate learning to behavioral aspects of students?

c. How can we implement the theories of learning in our schools?

In the late 1800s, many psychologists such as Sigmund Freud (1856-1939) and William James were extremely interested in understanding mental processes and their relationship to behavior. Freud's system of therapy was known as 'psychoanalysis' which states that psychological experiences are caused by biological drives and instincts ((Joseph \& Ann, 2006). He, therefore, used a method, named 'introspection' for self-observation and inner analysis thoroughly. John B. Watson argued against such methodology and proclaimed that it could not be verified scientifically so should not be a part of learning. Although Freud's methodology is still well known and used in the treatment of physical and mental illness, but due to the fact that unconscious mind cannot be verified under scientific conditions, it has lost its popularity among modern psychologists. Thus, such objections have resulted in shifting of thoughts from mental processes to observable behaviors (Joseph \& Ann, 2006).

William Wundt (1832-1920), set up the first laboratory of psychological study in 1879. He was purely interested in the study of consciousness, thought and emotions. The scientific technique used by him was called as 'introspection', which means understanding one's own actions and reactions consciously (Joseph \& Ann, 2006). Wundt's work was extended by Edward Bradford Titchener (1867-1927) who studied sensations and the ways they are formed while breaking consciousness into several parts. Both, Wundt and Titchener belonged to the school of thought named, 'structuralism'. For them, learning goals can be better understood through the analysis of experience (Joseph \& Ann, 2006).

Behaviorism was a very popular school of thought in the first half of the twentieth century in America. However, many psychologists criticized behaviorist's theories strongly. Such as Noam Chomsky (1959) argued that language is the phenomenon, that behaviorist could not solve. He also challenged Skinners Book on verbal behavior in 1959 and claimed that language complexities could not be grasped through simple behavioral explanations (Joseph \& Ann, 2006).

By the early 1960s, where psychology had faced much criticism for S-R relationships, there was a great interest in the human cognition among psychologists and linguists. After the world war second, information technology brought a revolution and introduced the concept of artificial intelligence in the form of computers. As computers simulate many 
cognitive processes like thinking, remembering and problem solving, many cognitive psychologists took them as an analogy for studying brain and mind. They focused their attention towards mind as a processing unit of a computer and formed a new science called 'cognitive psychology' (Robert \& Lauretta, 2013). In this connection, Ulric Neisser (1967), for the very first time, draws psychologists' attention towards Cognitive Psychology through his critical analysis of behaviorism and the introduction of its own journal in 1970. Neisser also is very famous in developing a model of cognitive processes in human beings (Joseph \& Ann, 2006). He analyzed that information passed through a series of stages, from perceptual processes of memory, can be retrieved when needed (Robert \& Lauretta, 2013). He has proposed the following model named 'bottom-up processing':

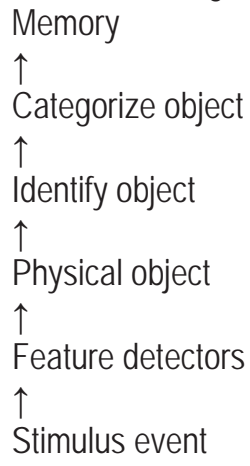

In the end of twentieth century, in the science of cognitive psychology, new subjects like linguistics, artificial intelligence and logical analysis through simulation emerged successfully. Longuet-Higgins, for the first time introduced the term, 'cognitive science' in 1973. It was a combination of subjects-psychology, computer science, linguistics, philosophy, and neuroscience (Robert \& Lauretta, 2013). Thus, cognitive psychology got benefits from the contributions in the field of computer science (computer models and processing techniques) and neuroscience (imaging techniques and brain activity) and opened a new window for learning theories in the field of educational psychology.

This study is based on critical review of literature with respect to cognitive and behavioral theories in Education. This is the best approach when we come across theoretical conflicts and try to reach out any solution to our practical problems. This would provide with a new insight to teachers, psychologists, and counselors with regard to implementation of educational cognitive theories successfully.

\section{Behavioral Theories}

William James (1842-1910) was one of the pioneers of functionalism who introduced the philosophy of pragmatism and functionalism. He focused on the study of the functions of mind and behavior rather than structure of mind, thus discussed the mental processes and their relation to the behavior (Fancher, R.E., 1996). For him, psychological processes must serve some functions or must be lost or changed (Joseph \& Ann, 2006).

Dewey was very much interested in mind and intelligence. While being focused on the present states, he took the world in an intelligent organization that cannot be explained by any theory. Locke interprets experiences in terms of simple sensations - the product of reflection whereas Dewey negates its importance by arguing that they are nonexperienced elements so should not be a part of purely empirical philosophy. He also made a distinction between the cognitional and non-cognitional activities of life and viewed thought as the servant of action. His descriptive method is not reflective indeed. Dewey supports biological and evolutionary theories to support his logical theory of learning. He also believed that the process of experience is purely conceptual and provides a base for belief formation and its measurement. According to him, it is the experience that is built up by the action of thought, not knowledge (Delton Thomas Howard, 1919).

Edward Thorndike (1874-1949), a psychologist whose work on learning theory paved the way for behaviorism. He was the first psychologist who brought a scientific approach to the study of learning. He introduced the technique that people learn through trial and error and in response to certain stimuli present in the environment (Hilgard \& Bower, 1975). His experiment with a cat in puzzle box cannot be ignored. The cat learns the new ways to escape from the puzzle box to get a piece of fish. In this experiment, time is relatively less when the cat is more trained. Hence concluded that any behavior followed by pleasant consequences is likely to be repeated and any behavior followed by unpleasant consequences is likely to diminish - thus named it the 'law of effect' (Beniafield \& John G.A. 1996; Thorndike, E.L. 1898). Then he also proved that the learned behavior diminishes without practice and strengthens with practice (Thorndike, 
1898).

According to the Behaviorist John, B. Watson, psychology is that branch of science, which involves human activity and conduct as subject matter. Psychologists find laws and principles through manifesting the men's reactions while adhering the systematic procedures and experiments. We can therefore predict human activity with a certainty of some stimuli. He has highlighted another concept that through the organization of societal rules, we can monitor man's actions and thus could provide laws and principles accordingly (John B. Watson, 1910). Thus behavioral learning theory focuses on only observable behavior while ignoring the cognitive processes and ignores learners reasoning and thinkingactivities that are important to the educational process (Collins, 2002).

During 1890s a Russian physiologist, Ivan Pavlov, through his experiment with dogs and other animals described the classical theory of learning in detail. In his theory the conditioned reflex is established by presenting the conditioned stimulus and natural stimulus simultaneously and repeatedly until the conditioned stimulus alone causes the secretion (Pavlov, 1897/1902).

In 1930s, other behaviorists were also investigating the human behavior in the light of stimulus and response mechanism such as John B. Watson, Edward Tolman (1886-1959), Edwin Guthrie and B.F. Skinner. Tolman is famous for his experiments on rats using mazes and argued that animals could learn about the facts and that learning is not dependent on the external stimuli. According to him, we do not need any reinforcement from the external environment to learn. Thus, he was an S-S theorist and such learning was called as 'Latent Learning' (Tolman, 1932).

Guthrie's (1886-1959) theory of contiguity is based on associations. He thinks that learning occurs at the first bond of stimulus-response (habit) and repetition is not always required (Stevenson Smith \& Edwin Guthrie, 1921).

B.F. Skinner (1904-1990) advanced the stimulus-response theory of learning (first introduced by Thorndike). His theory was based on the programmed learning in which he provided positive reinforcement in the reaction of a desired behavior and removed the reinforcement as a type of punishment to strengthen the desired behavior. According to him, the goal of psychology is not to study consciousness rather to control and predict the behavior. His theory has brought a great change in the whole system of education through the systematized approaches, structured curricula and other tools like textbooks, workbooks and other types of learning materials (Hilgard \& Bower, 1975).

Although behaviorists have contributed a lot, in understanding the fact how we learn yet they treat our mind as a blank board. They usually focuses on observable facts of behavior and in this connection also consider stimulusresponse connections as a basis for developing systematic research-based concepts and laws (Collins, 2002). However, behaviorism ignores the mental processes of learning, reasoning skills and thinking procedures as well as memory and information processing techniques all together.

\section{Cognitive Theories}

Educational psychologists have always been busy in investigating learning methodologies to make the knowledge more conducive, creative and authentic in terms of behavioral changes, habit-formations, thinking-styles, reflecting and proceeding towards higher goals. To achieve such a progressive and systematic approach towards learning, through only behavioral theories, was never possible. Thus dawn of the era of change in the basics, named cognitive theories of learning evolved. Cognitive approach also discusses the things that cannot be observed, unlike behaviorist theories, which focuses on the only observable phenomenon. Cognitive theorists are interested in finding out ways how to receive information, retain it, and then retrieve it. Such information would provide educationists with a tool to enhance learning among pupil and to help teachers in making their task more effective.

\subsection{Gestalt psychology}

The 'gestalt' is a German word, which means 'shape', 'form', or 'pattern'. In the early 1900s, Gestalt psychologists in response to structuralists who were interested in division of concepts to analyze the mental constructs, were more focused on studying the concepts as a whole. Some German psychologist like Max Wertheimer (1880-1943), Kurt Koffka (1886-1941) and Wolfgang Kohler (1887-1967) created the concept of the 'apparent movement' named as 'phi phenomenon' in which objects create illusions of different types when are close together in one space or time. Thus, they argue that human nature studies the events as a whole, therefore, things should not be discussed separately. While focusing on human perception and behavior, they introduced principles of perception and human behavior with the elaboration of specific conditions to which they belonged (Joseph \& Ann, 2006; Alison Thomas, 2004). 


\subsubsection{Laws of Perceptual Organization}

There are several perceptual laws developed to organize perceptual stimuli to predict human behavior accurately. For example:

- The law of good figure/ law of pragnanz in which reality is perceived in the simplest possible way.

- The law of proximity in which objects close to each other tend to form groups

- Law of similarity in which similar things tend to be grouped together.

- Law of contiguity in which lines tend to follow a smooth path whenever possible

- The law of closure in which we tend to see the incomplete figures as a whole while ignoring gaps and missing spaces.

Thus, all human perceptions assimilate with our experiences to help us in deriving meanings for our existing knowledge and we continue living better than before (Perls, 1992, 54).

Gestalt psychology has provided us with a great concept of wholeness in which it is assumed that the whole is better than the sum of its parts. For example, we perceive the meanings of a text, not the lines and word shapes separately. Similarly, we perceive the image of a person, not the eyes, nose, or lips separately (Pillsbury, 1933, 484-5)

Figure-Ground Principle of Gestalt psychology describes how we prioritize our needs, perceive experiences as a whole, and satisfy our needs while living in the moment. The figure could be any object, figure, or pattern that we are interested to look into or those we focus on and the ground is its related context, setting or environment. Sometimes we could not figure out which one is a figure or ground due to complexity of emotions and dynamic shifts of attention in brain (Perls, Hefferline \& Goodman, 1971, p. 25).

Wolfgang Kohler (1925), a gestalt psychologist, suggested that learning occurs in the form of an insight and it requires no training, no stimuli and no repetition to enforcement. Moreover, such learning is not observable (the idea, which is not approved by behaviorists). His experiment on chimpanzee to see how it learns to reach things outside the cage beyond its arms reach is very popular among psychologist.

Kurt Lewin (1890-1947) developed a cognitive theory named 'field theory'. He borrowed many ideas from the gestalt's laws of organization and explained that human behavior is affected by two types of forces/factors (positive and negative) and their direction (vectors). Such factors are also called as valences. He introduced the concept of 'life space' (in a simple term personal environment) in which human beings interact with other individuals or anything with a positive or negative valence in essence (Lewin, 1943).

\subsection{Piaget's Work on Cognitive Development}

Jean Piaget (1896-1980) a Swiss child psychologist, PhD in natural sciences, had remained interested in child psychology, explored cognitive theories from different angles and provided educational psychology with new schemes and learning concepts. He started his journey through noticing wrong answers of children and analyzing their answers carefully with respect to their age. He was of the view that thought processes in children are quite different from adults as they are not 'little adults'. They have their own unique way of thinking and interpreting the world, although it is true with respect to the age group they belong. Before going into the Piaget's stages of development, it is very important to take a note of his main concepts:

The first popular concept named 'Schemes' by Piaget means patterns of behavior occurred in dealing with the environment. It may be a very simple action of a child while reaching towards an object and can be very complicated task for an adult while solving any complex problem.

The second concept that Piaget calls 'Assimilation' is the procedure that we adopt while perceiving a new thing with the help of old knowledge. In this process, new information becomes part of the old one through assimilation. Therefore, it is very important for the new knowledge to have best similarity with the old or existing structure/scheme (Jeannette, Kim, 2002; Kurt and Rebecca, 1996). In contrast, in the concept of 'accommodation', one tries to modify the old schemas to accommodate the new ones. So new activities become part of the present schema and ultimately we learn (Kurt and Rebecca, 1996).

Piaget further elaborates that organism tries to maintain a level of equilibrium between the two things (stimuli and old schemes) either by creating new schemes or by adapting the old ones. One always seeks the state of equilibrium that is why it is called the 'law of equilibrium' in the process of learning (Jeannette, Kim, 2002).

In addition, there are certain principles of learning given by Piaget, quoted by Jeannette \& Kim (2002). For him, learning is an internal process of construction. The type of knowledge that children gain through abstracting properties 
from objects is called 'physical knowledge' and the process is called 'empirical abstraction'. Knowledge induced from activity is called 'logico-mathematical' knowledge and learning by constructing rules through activities is named as 'reflexive abstraction'. He argues that learning cannot be deduced from observation or experience alone rather it is subordinated to developmental needs. Therefore, for the children to learn, they must be able to assimilate in order to respond to new concepts or experiences. Piaget thinks that children learn not only by observation but also through a process of self-regulation - a process called equilibrium. In this process, they not only record what is going on, rather reorganize and coordinate their own activities to form rules and principles. Knowledge of children depends on the feedback in shape of questioning, contradictions, and reorganization of the thought-factors, which are often stimulated by social interaction. He concludes that learning is a result of reconstruction of ideas, so understanding lags behind the action. Piaget explains that the process of construction of knowledge is the result of two distinct but interrelated activities: discovery and invention (Jeannette, Kim, 2002; Hermina and Constance, 1970).

Piaget has also proposed different stages of learning with respect to developmental milestones. In the first stage/sensorimotor stage (0-2 years), babies start learning through imitation. They start forming of memory and are in the beginning of thinking stage. They begin to recognize the objects that they could not see for a while (law of object permanence). They are moving from reflex actions to purposeful behaviors (Sharon L. Pontious, 1982).

In the second stage of development (2-7years) /Preoperational stage, children start using symbols and start thinking more logically towards one object but still are lack of empathy and its related traits. In the third stage (7-11), named concrete operational stage, one is able to solve concrete problems and understands the laws of conservation. One could easily grasp the concept of classification, reversibility and could re-organize objects in the logical fashion. Then in the last stage (11-adult) named as 'formal operational', one being very much aware of one's identity, can easily solve abstract queries, scientific theories and social issues in the most logical manner (Sharon, 1982).

On the one hand, Piaget has pioneered a great revolution in the field of education and psychology, and on the other side, his theory has faced much criticism as well. Many investigators thought his theory to be abstract, vague, difficult to verify and argued that the logical structures Piaget proposed did not exist. Some argued that Piaget's method of interviewing children was too clinical and methods of data collection were non-scientific (Jeannette, Kim, 2002).

\subsection{Vygotsky's Theory of Cognitive Development}

Russian psychologist Lev Vygotsky's (1896-1934) theory of cognitive development is very popular among educationists, psychologists and scientists of social sciences. For him children are active learners and construct their knowledge actively. He was born in the same year as Piaget was born, but his theories gained no acknowledgment from Americans for many years until 1960 when one of his English translations (thought and language) appeared in the market. Since then, Americans as well as other educators from all over the world became widely interested in his writings about learning and its implications in education. It took sixteen years from then (in 1978) for Vygotsky to achieve a recognition in the field of education (Fred Newman \& Lois Holzman, 1993).

\subsubsection{Vygotsky's assumptions:}

- Child's cognitive skills cannot be measured until her stage of development is carefully defined. For him, it is very important to measure how children form concepts, and transform them from one stage to another and such processes must be observed throughout their development gradually and subsequently (Harry Daniels, 2008).

- Cognitive skills are mediated through psychological tools or mediators that facilitate in transforming and assessing mental processes and functions such as language, words, counting systems, mnemonic techniques, algebraic symbols, artwork, writing patterns, maps, diagrams, drawings and other sorts of signs and discourse. Such tools nature is social and artificial rather than organic. He proposed that language is the most important tool in this regard and for children it serves as a tool to plan activities and solve problems in daily life (Harry Daniels, 2008).

- Vygotsky claimed that cognitive skills originate in socio-cultural backdrop (Harry Daniels, 2005). For him developmental constructs like memory, attention, and reasoning skills need learning tools that are also part of a society such as language, mathematical calculations, and memory strategies. Hence, knowledge is situated as well as collaborative, which needs tools, artifacts and communities or cooperative activities (Reid et al., 1982). 


\subsubsection{Zone of Proximal Development:}

The unique range of tasks that a child can accomplish with the help of an adult or teacher and that are not possible to furnish alone is thought as the zone of proximal development according to Vygotsky. The level a child gains in problem solving a skill independently is called the lower limit of the ZPD. The level of problem that a child accepts to solve under an adult's supervision is called upper limit of ZPD (Harry Daniels, 2005). When an adult guides a child and changes the level of support accordingly, it is called 'scaffolding'. If the task a child is learning is new, the adult or the person who is guiding can directly instruct her. When the child gains some competence, the adult would change the strategy and would provide with minimum instruction as to assist learning. In this connection, dialogues play an important role between the child and the helper. Children usually keep disorganized, unsymmetrical and rich concepts that can be transformed into more systematic, logical, rational and organized ones with the help of a skilled, vigilant and trained instructor.

Vygotsky (1962) argues that children use language as a tool to communicate, guide, plan, and monitor their activities in a self-regulatory manner and this type of use is called 'inner speech'. For him such speech is vital to young children's cognitive development. Vygotsky proposed that language and thought develop independently of each other and later on emerge. At first language is used to communicate with others for a long period then we focus on our thoughts inwardly through internal speech. The transition period usually refers to from three to seven years. The speech that is first used for language acquisition, internalized in the form of inner speech, and then became part of thoughts of children. Children must use of inner speech as a tool to become more socialized and competent. Piaget views the children's language as nonsocial, or egocentric speech and their self-talk being immature thought as compared to Vygotsky's view of language( that states the language is socially based, governs and guides the children from very early stage) (Ellin et al. 1999). It is equally evident that both Vygotsky and Piaget have given due attention to social relationships and cultural aspects in the process of learning and knowledge enhancement (Leslie et al., 1997). However, researchers have supported Vygotsky's views on the language's positive role in children's development.

\subsubsection{Concept Development}

Vygotsky studied how we develop the concepts and interact with each other based on them. For him, children can learn about the concept of self through interacting with adults only. Vygotsky argued that there are two types of concepts: scientific and everyday concepts. Scientific concepts are formed based on systematic, organized, and hierarchical thoughts whereas everyday concepts are linked to particular contexts. The everyday concepts bring richness and signification of thought into systematized and organized scientific concepts. When scientific concepts meld with such everyday concepts, they become alive and become rules and laws of life (Harry Daniels, 2005).

\subsubsection{Information Processing Model}

The information processing theorists explain terms and conditions that are very common among linguistics, computer scientists, and information processing educationists to explain the thought processes. They think human beings as computers who keep the information, process the new information, and retrieve it accordingly.

During the first half of the 20th century, Sir Frederick Bartlett investigated memory for a long time, and proposed that human beings are active learners who remember things or construct their memory actively while understanding and interpreting the information and meanings of the subjects and do not concentrate on the material solely. He opposed the previous view on memory, which focused on rote learning techniques only. According to him, people usually construct a schema while remembering something and it helps them organize and make sense of new concepts (Robert \& Lauretta, 2013).

Chomsky was very popular linguist in the early years of cognitive revolution. Chomsky has presented a complete structure of language development and its implications in psychology and education. He, contrary to skinner who explained language acquisition through classical and operant conditioning, argued that language development is based on specific principles, not on the learning procedures that include animals in place of humans to generalize the concepts. For him, humans are the only species that possess language and the most important feature of language is 'creativity'. He has introduced the rules for cognitive modularity according to which, the rules for learning a language are located in a specific module, and the rules for learning other skills like vision, mathematical/analytical skills or artistic skills are located in other (different) modules. Thus, the Chomsky's rules for language processing have provided us a base for the information-processing model of cognition (Robert \& Lauretta, 2013). 
The researchers in computer science proposed that human beings could also be studied as informationprocessing machines especially in the subjects, which have common grounds. Although such approach needs to face many challenges, yet it has proved a useful base for the cognitive/learning developmental studies (Robert \& Lauretta, 2013).

As, in the recent years, Information processing theory has become quite compatible to genetic epistemology; while making a new theory of knowledge, one must consider the facts and principles derived in both schools of thought (Jeannette, Kim, 2002).

\section{Educational Implication of Piaget's Theory}

Piaget always supported active learning in children and strongly negates rote or passive learning techniques. For him, children learn actively by making discoveries, reflecting and discussing things that paves the way for future inventions. Therefore, the teacher must encourage students to discuss, reflect, analyze, understand and create things rather than imitating or rote learning blindly or carelessly (Kurt and Rebecca, 1996).

Teachers must facilitate students by asking queries, questions, and posing problems to solve; they must stimulate students thinking by providing them with situations to create something ; they should listen to them carefully as well as observing them minutely and then trying to suggest new ways to learn better.

Children come to class with many great ideas about their world, space, time, quantity and causality that are different from adults views and constructions about these concepts so teachers must keep in mind their students developmental stage of cognition to respond them at the same level of understanding and with the most relevant logic.

The teacher may use ongoing assessment techniques and hold conferences to discuss strategies of thinking and reasoning in classrooms.

Piaget has promoted natural pace of learning among children. He thought children should not be pushed towards higher cognitive goals in very early age; otherwise they will become passive learners instead of being active learners. Some parents put too much pressure on their infant's mind and try to raise their vocabulary level higher than the present one in the least possible time. According to Piaget, it is not the recommended practice rather infants should develop their cognitive skills naturally.

Piaget has recommended that the settings of classrooms must fit for exploration and discovery needs of students. Before Piaget's time, classrooms were more traditional with workbooks and assignment type materials. In Piaget's suggested classrooms, especially first and second grade classrooms, teachers first observe and explore students' interest in activities and then arrange a set of functions to start learning. In a math classroom, for example, students can be asked to count their money or to divide their toys among their peers. Teachers can use different types of games to stimulate cognitive development among children for example, dominoes that teach about even number combinations. In exploring all activities, teachers must promote peer interaction in classrooms to help students learn actively and at the highest possible pace.

\section{Educational implication of Vygotsky's theory}

According to Vygotsky, there are three basic most important features of human beings: they have language, they innovate their own tools, and then they transmit the discoveries and inventions from one generation to the next through languages, institutions, and schooling (Jeannette, Kim, 2002). He has provided us with means of teaching that using the ZPD, can assist children's learning and improve their performance (Harry Daniels. 2005).

The means of teaching proposed by Vygotsky are as follows:

- Modeling: Modeling or providing students an example of performance to imitate would help them to remember the information and experiences.

- Feedback: It is the process of providing information on a performance to be compared to the standard and to self- correction.

- Contingency management: It is to apply reinforcement and punishment to correct the behavior or to help learning among students.

- Instructing: Sometimes, it is very important for a teacher to select the correct response, and decide about the right answer for the learner to assist him especially when he is incapable of understanding the logic behind the task performed.

- Questioning: It assists the learner in producing a mental operation that a learner could not resolve while sitting 
alone.

- Cognitive Structuring: It is the explanation or organized beliefs and perceptions that help learners make new schemata or understand new knowledge.

- Task Structuring: It helps the learners by modifying the tasks to fit their skills into the ZPD.

Keeping the above in view, teachers should provide guidance to pupils according to their own ZPD and continue providing instruction to help learning through finding out new ZPDs until or unless the students master a skill or learn a topic to its highest possible level.

In addition teachers must use the technique of 'scaffolding' to assist students in taking initiatives, learning new skills, and attaining a knowledge level that they could not be able to master alone. Thus, the children's system of activity should be measured on two different grounds: first based on their organic development and secondly based on their degree of mastery in the use of tools (Harry Daniels. 2005).

Vygotsky believed that standardized tests in schools could not assess children's learning level perfectly. Instead, the proper use of ZPD would only solve the problem. Teachers should make use of ZPD to assess students learning level in advance and during classroom. Formal is necessary to start the instruction with the appropriate method to suit the needs of the child, and later is important to speed up learning to the highest possible level of the students' potentials. He further elaborates the concept of ZPD and distinguishes it from I.Q by arguing that although I.Q and ZPD both are thought as learning potentials, they should not be taken in the same sense while assessing children's learning. As ZPD being quite different from I.Q, originates in a social environment whereas I.Q is thought as a property of the child and generally is biologically based.

For Vygotsky, language plays a vital role in the development of children. They start learning symbols from a very early age, between 3 to 7 years, and start internalizing the concepts through private or internal speech. Thus, it is very important for teachers to encourage private speech among children as it helps them learn and become social. Such selftalk is a great tool to facilitate self-correction and self-regulation in schools and out of the school areas.

Vygotsky has encouraged social interaction among students as it helps them learn new tools like language, problem solving and memorizing. For him, it is very important to involve more skilled peers as well as teachers or adults to help students learn effectively in classrooms (Vygotsky, 1978, p.84). He thought isolation is no place to learn, as we all including children, parents, peers, co-workers and members of a society interact and collaborate with each other. Thus in schools, learning should not only focus on skills rather should encompass other subjects vital to social needs of students required especially after completing basic education.

\section{References}

Alison Thomas-Cottingham, 2004. Psychology Made Simple. The Philip Lief Group, Inc, N.Y. Beniafield, John G.A. 1996. A History of Psychology. Allyn and Bacon, Massachusetts.

Collins, A. 2002. How Students learn And How Teachers Teach, in: Bybee, R.W. (Ed.), Learning Science and the Science of learning .NSTA Press, Arlington, VA.

Daniel L.Schacter, Daniel T. Gilbert, \&Daniel M. Wegner, 2009. Psychology (2nd Edition). Worth Publishers, N.Y. P -264

Delton Thomas Howard, 1919, John Dewey's Logical Theory. Longmans, Green, \& Co., N.Y.

Ellin Kofsky Scholnick, Katherine Nelson, Susan A.Gelman, \& Patricia H.Miller. 1999. Conceptual development: Piaget's Legacy. Lawrence Erlbaum Associates, Inc., Mahwah, New Jersey, London.

Ellwood P.Cubberley.1900. Readings in the history of Education. Houghton Mifflin Company, N.Y.

Fancher, R.E. 1996. Process of Psychology (third Edition). Norton \& Company, N.Y. P. 247

Fred Newman \& Lois Holzman, 1993. Lev Vygotsky. Routledge, London and N.Y.

Harry Daniels, 2005. An introduction to Vygotsky. Routledge, N.Y.

Harry Daniels. 2008. Vygotsky and Research. Routledge, London and N.Y.

Hilgard, E.R. \& Bower, G.H.1975. Theories of learning. Englewood Cliffs, Prentice Hall, Inc., N.Y.

Hermina Sinclair and Constance Kamii. 1970. Some Implications of Piaget's Theory For Teaching Young Children: The School Review. Vol 78, No 2. 169-183.

Jeanette McCarthy Gallagher \& D.Kim Reid. 2002. The learning theory of Piaget and Inhelder. Authors Choice Press, N.Y.

John B. Watson.1910. Psychology: from the standpoint of a behaviorist. J. B. Lippincott Company, Philadelphia and London.

Joseph G.Johnson \& Ann L. Weber, 2006. Introduction to Psychology (second Ed). Collins, N.Y.

Kurt W.Fischer and Rebecca W. Hencke. 1996. Infants Construction of Action in Context: Piaget's Contribution to Research on Early Development. Psychological Science. Vol. 7, No. 4. Pp.204-210.

Leslie Smith, Julie Dockrell \& Peter Tomlinson.1997. Piaget, Vygotsky and Beyond. Routledge, N.Y.

Lewin K.1943. Defining the "Field at a Given Time." Psychological Review. 50. 292-310.

Pavlov, I. P.1897, 1902. The Work of the Digestive Glands. Griffin, London. 
Perls Frederick, Ralph Hefferline, and Paul Goodman. 1994. Gestalt therapy: Excitement and growth in the human Personality. Gestalt Journal Press, Highland, NY.

Perls, Laura.1992. Concepts and Misconceptions of Gestalt Therapy, Journal of Humanistic Psychology, Vol. 32 No. 3, 50-56

Pillsbury, W. B. 1933. The Units of Experience-Meaning or Gestalt, The Psychological Review, Vol 40, No 6. 481-497

Robert W.Weisberg \& Lauretta M. Reeves.2013. Cognition. John Wiley \& Sons, Inc., Canada.

Reid, T., Forrestal, P. and Cook, J. 1982. Small Group Work in the Classroom: language and Learning Project. Education Department, Western Australia.

Stevenson Smith \& Edwin Guthrie .1921. Chapters in General Psychology. University of Washington Press, America.

Sharon L. Pontious. 1982. Helping Children Understand: The American Journal of Nursing. Vol. 82, No 1. 114-117.

Thorndike, E.L. 1898. Animal Intelligence: Psychological Monograph: General and Applied, 2 (4). P.109.

Thorndike, E.L. (1898). Animal Intelligence: An experimental study of the associative processes in animals. Macmillan Co., NY and London.

Tolman, E. C.1932. Purposive Behavior in Animals and Men. Century, N.Y.

Vygotsky L.S. 1978. Mind in Society. The development of higher psychological processes. Harvard University Press, Cambridge: MA. 